\title{
Compliance/Adherence to Glaucoma Medications-A Challenge
}

\author{
${ }^{1}$ Rajendra K Bansal, ${ }^{2}$ James C Tsai \\ ${ }^{1}$ College of Physicians and Surgeons, Columbia University, New York \\ ${ }^{2}$ Yale University School of Medicine, New Haven, Connecticut
}

\section{INTRODUCTION}

Glaucoma is the second leading cause of blindness in the United States and Worldwide. ${ }^{1}$ Although it is a multifactorial disease, it is widely recognized that elevated intraocular pressure (IOP) is a major risk factor for the development and progression of glaucomatous optic neuropathy (GON). A number of landmark studies in the last decade have firmly established the relationship between elevated IOP and increased risk of visual loss in patients with ocular hypertension $(\mathrm{OH})$, primary open angle glaucoma (POAG), and normal pressure glaucoma (NPG) ${ }^{2-5}$ At the present time, lowering IOP is the only proven method of slowing optic nerve damage and visual field progression. ${ }^{6}$ Although medical therapy, laser trabeculoplasty and surgical treatment are reasonable options for the initial treatment of glaucoma, most patients initially receive one or more medications to lower IOP. If the drops control IOP adequately, the patient is advised to remain on therapy indefinitely. Glaucoma is a chronic disease with no symptoms initially and is therefore susceptible to patient's non-adherence to prescribed therapy. Despite the availability of effective pharmacologic therapies, non-adherence in patients with glaucoma has been reported to vary from 24 to $59 \%{ }^{7-9,20}$ In a large retrospective Cohort study that used health insurance claims data from 5300 patients, nearly $50 \%$ of patients discontinued glaucoma medications within 6 months and only $37 \%$ of all patients got all their prescription filled at three years after the initial dispensing. ${ }^{7}$

The terms "adherence" and "compliance" are used interchangeably with "adherence" being preferred more to imply active participation of a patient to follow prescribed medical regimen. "Persistency" is another term used for continuous use of glaucoma medications and may be influenced by patient adherence and preference.

There is a wide body of literature and excellent reviews available regarding adherence and persistency in patients with glaucoma and ocular hypertension. ${ }^{8-14}$ But, in an evidencebased review of quantitative studies on non-compliance with hypotensive treatment of glaucoma, there was no strong evidence supporting a relation between non-compliance and progression of visual fields loss. ${ }^{14}$ In a recent study ${ }^{10}$ to confirm findings from a claims database and by conducting telephone interviews with physicians and patients, the authors cautioned that one of the reasons for the low rates of measured cooperation may be due to eyedrop samples given to patients by physicians. Similarly, physicians may stop prescribing eyedrops after an initial trial, producing the false appearance of a lack of adherence.

The American Glaucoma Society (AGS) started an initiative on "Patient care improvement project" by soliciting ideas from ophthalmologists, allied health personnel (ophthalmic nurses and technicians) and patients themselves regarding perceived barriers to compliance. The present article provides an update on understanding challenges of non-compliance and ways to minimize it.

\section{Measuring Compliance Adherence}

Adherence measurement can be done by direct or indirect methods. ${ }^{11}$ Direct methods are more objective but expensive and include observation, measurement of drug concentration or metabolites in blood or urine and detection of biologic markers. Indirect methods include patient questionnaires, pill counts, rate of prescription refills, assessment of clinical response, electronic monitors and measurement of physiological markers. Each method has unique advantages and disadvantages as listed (Table 1).

Patient self-report involving either answering to questionnaires or interview by a trained personnel is relatively simple and cheapest way to address non-compliance. However, reporters are subject to recall bias and usually overestimate compliance to meet perceived physician expectation. ${ }^{15}$ Also, selection bias may occurs as patient willing to participate may be more compliant or report more compliance than they observe. Rates of medical compliance according to self-report have varied considerably from 39 to $85 \% .^{16-20}$

Electronic monitoring, ${ }^{21-25}$ an indirect method of estimating patient compliance is more accurate but expensive and limited by the fact that opening the unit does not confirm that a dose 
Table 1: Methods of measuring adherence

\begin{tabular}{|c|c|c|}
\hline Test & Advantages & Disadvantages \\
\hline \multicolumn{3}{|l|}{ Direct methods } \\
\hline Directly observed therapy & Most accurate & $\begin{array}{l}\text { Patients can hide pills in the mouth and then discard them; } \\
\text { impractical for routine use }\end{array}$ \\
\hline $\begin{array}{l}\text { Measurement of the level of medicine } \\
\text { or metabolite in blood }\end{array}$ & Objective & $\begin{array}{l}\text { Variations in metabolism and 'white-coat adherence,' } \\
\text { can give a false impression of adherence, expensive }\end{array}$ \\
\hline $\begin{array}{l}\text { Measurement of the biologic } \\
\text { marker in blood }\end{array}$ & $\begin{array}{l}\text { Objective; in clinical trials, can also } \\
\text { be used to measure placebo }\end{array}$ & $\begin{array}{l}\text { Requires expensive quantitative assays and collection } \\
\text { of bodily fluids }\end{array}$ \\
\hline \multicolumn{3}{|l|}{ Indirect methods } \\
\hline $\begin{array}{l}\text { Patient questionnaires, patient } \\
\text { self-reports }\end{array}$ & $\begin{array}{l}\text { Simple; inexpensive; the most useful } \\
\text { method in the clinical setting }\end{array}$ & $\begin{array}{l}\text { Susceptible to error with increases in time between } \\
\text { visits; results are easily distorted by the patient }\end{array}$ \\
\hline Pill counts & $\begin{array}{l}\text { Objective, quantifiable, and easy to } \\
\text { perform }\end{array}$ & Data easily altered by the patient (e.g. pill dumping) \\
\hline Rates of prescription refills & Objective; easy to obtain data & $\begin{array}{l}\text { A prescription refill is not equivalent to ingestion of } \\
\text { medication; require a dosed pharmacy system }\end{array}$ \\
\hline $\begin{array}{l}\text { Assessment of the patient's } \\
\text { clinical response }\end{array}$ & Simple; generally easy to perform & $\begin{array}{l}\text { Factors other than medication adherence can affect } \\
\text { clinical response }\end{array}$ \\
\hline Electronic medication monitors & $\begin{array}{l}\text { Precise; results are easily quantified; } \\
\text { tracks patterns of taking medication }\end{array}$ & $\begin{array}{l}\text { Expensive, requires return visits and downloading data } \\
\text { from medication vials }\end{array}$ \\
\hline $\begin{array}{l}\text { Measurement of physiologic } \\
\text { Markers (e.g. heart rate in patients taking } \\
\text { beta-blockers) }\end{array}$ & Often easy to perform & $\begin{array}{l}\text { Marker may be absent for other reasons } \\
\text { (e.g. increased metabolism, poor absorption, } \\
\text { lack of response) }\end{array}$ \\
\hline Patient's diaries & Help to correct for poor & Easily altered by the patient \\
\hline $\begin{array}{l}\text { When the patient is a child, questionnaire } \\
\text { for caregiver or teacher }\end{array}$ & Simple; objective & Susceptible to distortion \\
\hline
\end{tabular}

was administered or instilled properly. ${ }^{25}$ Most of the times, the patient omits taking a medication rather than overdosing ${ }^{21-22}$ or delaying the timing of the dose. ${ }^{24}$ Moreover, patient improve their level of compliance just prior to a scheduled doctor's appointment. ${ }^{21}$ This may result in controlled IOP but continued progression of visual field loss. Unless non-adherence to the glaucoma regimen is suspected, it may be difficult to determine whether disease progression is due to lack of efficacy, medications tachyphylaxis or patient non-compliance. ${ }^{26}$

A review of a large number of studies in which electronic monitors were used also concluded that adherence was inversely proportional to frequency of dosing. ${ }^{15}$

\section{Barriers to Compliance}

Many researches have started to find out why patients do not adhere to their medical regimen . But research extending back for more than 20 years has repeatedly demonstrated that physician are poor judges of which patient are compliant and which are not. Some of the common reasons cited for noncompliance are forgetfulness, inability to instill their eye drops accurately, inconvenience or frequent dosing, cost of medicine, and medication side effects. ${ }^{19,20,27,28}$

Tsai et al $^{16}$ developed a taxonomy (systematic classification) of barriers to adherence in glaucoma patients. They described 71 unique situational obstacles to medication adherence and grouped them into four separate categories: situational/ environmental factors (49\%), regimen factors (32\%), patient factors (16\%) and provider factors (3\%) (Table 2).

Such taxonomies have guided development of individual treatment algorithms to optimize patient education and problem solving regarding the prescribed therapeutic regimen.

\section{Regimen-related Factors}

The cost, complexity of taking multiple medications for multiple diseases, change in dosing schedules and side effects of medications are all well known reasons for non adherence. Co-morbidities like poor vision and arthritis in glaucoma patients affects their ability to instill their eye drops. Once-a day dosing with prostaglandin and beta-blockers have a better persistency. ${ }^{7}$ 


\begin{tabular}{|c|c|}
\hline Categories & Sample statement \\
\hline \multicolumn{2}{|l|}{ Regimen Factors } \\
\hline Refill & I only forget to take my drops when I run out \\
\hline Cost of medication & $\begin{array}{l}\text { When my insurance stopped paying for my } \\
\text { medication, I didn't take my drops }\end{array}$ \\
\hline Complexity & $\begin{array}{l}\text { It was harder when I was taking four } \\
\text { medications; now that I am taking three, it is } \\
\text { better. }\end{array}$ \\
\hline Change & $\begin{array}{l}\text { When I first started taking the drops, I had a } \\
\text { harder time remembering }\end{array}$ \\
\hline Side effects & $\begin{array}{l}\text { I decided to quit taking my drops because I had } \\
\text { a bad reaction from them }\end{array}$ \\
\hline \multicolumn{2}{|l|}{ Patient Factors } \\
\hline Knowledge/skill & Sometimes I miss my eye when taking my drops \\
\hline Memory & Sometimes I just forget to take my drops \\
\hline Motivation/health beliefs & $\begin{array}{l}\text { I quit taking my drops because I didn't see } \\
\text { benefit from them and didn't think they were } \\
\text { working }\end{array}$ \\
\hline Co-morbidity & $\begin{array}{l}\text { It is harder to keep track of my drops because I } \\
\text { am taking so many other medications }\end{array}$ \\
\hline \multicolumn{2}{|l|}{ Provider Factors } \\
\hline Dissatisfaction & $\begin{array}{l}\text { I quit taking my drops because I was dissatisfied } \\
\text { with my doctor's care }\end{array}$ \\
\hline Communication & $\begin{array}{l}\text { I stopped taking my drops because I didn't } \\
\text { understand initially that I need to take them } \\
\text { forever }\end{array}$ \\
\hline \multicolumn{2}{|l|}{$\begin{array}{l}\text { Situational/Environmental } \\
\text { Factors }\end{array}$} \\
\hline $\begin{array}{l}\text { Accountability/lack } \\
\text { of support }\end{array}$ & $\begin{array}{l}\text { Living alone, I had problems taking my } \\
\text { drops; now I live with my daughter and have } \\
\text { no problems }\end{array}$ \\
\hline Major life events & $\begin{array}{l}\text { Two years ago when my wife died, I had a hard } \\
\text { time taking my drops. }\end{array}$ \\
\hline Travel/away from home & $\begin{array}{l}\text { When I am on vacation, it is more difficult to } \\
\text { take my drops }\end{array}$ \\
\hline Competing activities & $\begin{array}{l}\text { I miss my drops on Sunday morning when I go } \\
\text { to church }\end{array}$ \\
\hline Change in routine & $\begin{array}{l}\text { Lifestyle changes that occur on weekends, such } \\
\text { as not getting up at a normal hour, cause me to } \\
\text { forget to take my drops. }\end{array}$ \\
\hline
\end{tabular}

Reprinted from Tsai JC, et al. J Glaucoma 2003;12:393-398.

\section{Patient-related Factors}

Patients appear to need reinforcement and education regarding their disease and medication. Patients with inadequate health literacy will have difficulty in understanding and interpreting most written health texts and instructions. Such patients are also more likely to take medications incorrectly. In older patients, factors such as vision, hearing, poor cognitive ability and other mental disorders like Alzheimer and dementia can complicate their medication adherence, if they have no external help.

\section{Provider-related Factors}

Adherence is better achieved where physician take proactive role in discussing with patient regarding their disease and use of medication. An open discussion regarding dosing, side effects, cost of medication, early and more frequent followups in the beginning usually help in developing a better understanding between patient and the physician.

\section{Situations/Environmental Factors}

Socio-cultural, racial and ethnic factors may influence medication adherence.

Insufficient family support, living alone and deaths in the family are also known reasons for non-compliance.

\section{American Glaucoma Society (AGS ) Initiative}

The AGS supported by an unrestricted educational grant from Pfizer Ophthalmics started a "Patient Care Improvement Project" with the goal to identify "best practice” ideas for enhancing and supporting patient compliance. The ideas were solicited from ophthalmologists, allied health personnel (ophthalmic nurses and technicians) and patients themselves. With 400 registered participants (144 physicians, 120 support personnel and 136 patients), forgetfulness emerged as the leading barrier to compliance. Other common hurdles included patient's lack of strength or dexterity to open and use eye drops bottles, difficulties with timing and scheduling, medications side effects and the cost of medications.

43 winning ideas have been identified. The AGS is now in the process of developing compendium of the winning ideas and disseminating this through AGS website www.glaucomaweb.org and printed educational and patient care material, including those developed by the American Academy of Ophthalmology (AAO). Further research is also underway into developing novel ideas in the areas of compliance, adherence and persistence to therapy.

\section{Pearls to Improve Patient Compliance}

The AGS has grouped the ways to improve compliance into three categories:

1. Practical tools and tips like memory aids, appointment reminders, timing and tracking tools.

2. Ideas for drug companies like modification of bottle design to get eye drops consistently and accurately or simply knowing how much liquid is left in the bottle.

3. Ways to trigger and support the self-care impulse by highlighting consequences of not treating the disease, using a team approach, enlisting the patient's input and providing educational materials. 


\section{CONCLUSION}

Noncompliance is a frustrating issue in the management of a glaucoma patient. It leads to switching and addition of other medications and ultimately to unnecessary surgical procedures. The solution is likely to be multi-dimensional and should be individualized for the patient.

The AGS initiative of a "patient care improvement project" and future research into identifying novel ideas for improvement in the areas of compliance, adherence, and persistency to therapy should guide physicians to develop individualized strategies to treat glaucoma patients in the ever changing medical environment.

\section{REFERENCES}

1. Quigley HA, Broman A. The number of people with glaucoma worldwide in 2010 and 2020. Br J Ophthalmol 2006;90:262-7.

2. Kass MA, Heuer DK, Higginbotham EJ, et al. The Ocular Hypertension Treatment Study: a randomized trial determines that topical ocular hypotensive medication delays or prevents the onset of primary open-angle glaucoma. Arch Ophthalmol 2002;120:701-13.

3. The AGIS investigators. The Advanced Glaucoma Intervention Study (AGIS) 7: The relationship between control of intraocular pressure and visual field deterioration. Am J Ophthalmol. 2000;130:429-40.

4. Collaborative Normal-Tension Glaucoma Study Group. Comparison of glaucomatous progression between untreated patients with normal-tension glaucoma and patients with therapeutically reduced intraocular pressures. Am J Ophthalmol. 1998;126:487-97.

5. Collaborative Normal-Tension Glaucoma Study Group. The effectiveness of intraocular pressure reduction in the treatment of normal-tension glaucoma. Am J Ophthalmol. 1998;126:498505.

6. Wax MB, Camras CB, Fiscella RG, Girkin C, Singh K, Weinreb RN. Emerging perspectives on glaucoma: optimizing 24-hr control of intraocular pressure. Am J Ophthalmol. 2002;133 (Supp): S1-10.

7. Nordstrom BL, Friedman DS, Mozaffari E, Quigley HA, Walker AM. Persistence and adherence with topical glaucoma therapy. Am J Ophthalmol 2005;140:598-606.

8. Rotchford AP, Murphy KM. Compliance with medical therapies for glaucoma. Eye 1998;12:234-6.

9. Gurwitz JH, Glynn RJ, Momane M, et al. Treatment for glaucoma: adherence for the Elderly. Am J Public Health 1993;83:711-6

10. Quigley HA, Friedman DS, Hahn SR. Evaluation of practice patterns for the care of open-angle glaucoma compared with claims data- The glaucoma adherence and persistency study. Ophthalmology 2007;114:1599-606.

11. Osterberg L, Blaschke T. Adherence to medication. N Engl J Med 2005;353:487-97.

12. Schwartz GF. Compliance and persistency in glaucoma followup treatment. Curr Opin Ophthalmol 2005;16:114-21.

13. Tsai JC. Medication adherence in glaucoma: approaches for optimizing patient compliance. Curr Opin Ophthalmol 2006;17:190-5.
14. Olthoff CM, Schouten JS, Van de Borne BW, Webers CA. Noncompliance with ocular hypotensive treatment in patients with glaucoma and ocular hypertension: an evidence-based review. Ophthalmology 2005;112:953-61.

15. Claxton AJ, Cramer J, Pierce C. A systematic review of the associations between dose regimens and medication compliance. Clin Ther 2001;1296-310.

16. Tsai JC, McClure CA, Ramos SE, et al. Compliance barriers in glaucoma: a systematic classification. J Glaucoma 2003;12:3938.

17. Jampel HD, Schwartz GF, Robin AL, et al. Patient preference for eye drop characteristic: a willingness-to-pay analysis. Arch Ophthalmol 2003;121:540-6.

18. Rotchford AP, Murphy KM. Compliance with timolol treatment in glaucoma. Eye 1998;12:234-6.

19. Konstad AG, Maskaleris G, Gratsonidis S, Sardelli C. Compliance and view point of glaucoma patients in Greece. Eye 2000;14:752-6.

20. Patel SC, Spaeth GL. Compliance in patients prescribed eye drops for glaucoma. Ophthalmic Surg. 1995;26:233-6.

21. Kass MA, Meltzer DW, Gordon M, et al. Compliance with topical pilocarpine Treatment. Am J Ophthalmol 1986;101:51523.

22. Kass MA, Gordon M, Morley RE, et al. Compliance with topical timolol treatment. Am J Ophthalmol 1987;103:188-93.

23. Norell SE. Monitoring compliance with pilocarpine therapy. Am J Ophthalmol 1981;92:727-31.

24. Paes AH, Bakker A, Soe-Agnie CJ. Impact of dosage frequency on patient Compliance. Diabetes Care 1997;20:1512-7.

25. Krousel-Wood M, Thomas S, Muntner P, Morisky D. Medication adherence: a key factor in achieving blood pressure control and good clinical outcomes in hypertensive patients. Curr Opin Cardiol 2004;19:357-63.

26. Bansal RK, Tsai JC. Advances in the management of primary open-angle glaucoma. In Nema HV, Nema N (Eds). Recent advances in ophthalmology-8. Jaypee Brothers, Daryaganj, New Delhi 2006;130-48.

27. Taylor SA, Galbraith SM, Mills RP. Causes of non-compliance with drug regimens in glaucoma patients: a qualitative study. J Ocul Pharmacol Ther 2002;18:401-9.

28. Noecker RJ. Motivation and patient compliance. Rev Ophthalmol 2005:97-9.

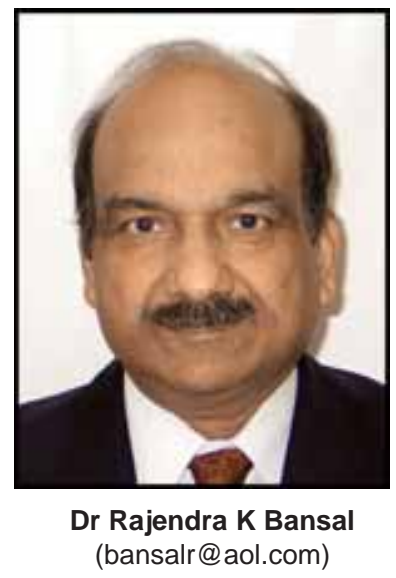

